\title{
Cardiovascular risk factors and determinants of clinical outcomes in type 2 diabetic patients at a tertiary-care centre
}

\author{
Maria Jose $^{1,3}$, Aparna Manjunath ${ }^{1}$, Ganapathy Bantwal ${ }^{2}$, Denis Xavier ${ }^{1 *}$
}

\begin{abstract}
${ }^{1}$ Department of Pharmacology,
${ }^{2}$ Department of Endocrinology, St John's National Academy of Health Sciences, Bangalore, India

${ }^{3}$ Department of Pharmacology, Jubilee Mission Medical College and Research Institute, Thrissur, Kerala, India
\end{abstract}

Received: 03 August 2016 Accepted: 03 September 2016

*Correspondence to:

Dr. Denis Xavier,

Email: denis@sjri.res.in

Copyright: (C) the author(s), publisher and licensee Medip Academy. This is an openaccess article distributed under the terms of the Creative Commons Attribution NonCommercial License, which permits unrestricted noncommercial use, distribution, and reproduction in any medium, provided the original work is properly cited.

\begin{abstract}
Background: The prevalence of type 2 diabetes mellitus (T2DM) is growing rapidly worldwide. The global burden of T2DM in 2013 was 382 million and projected to 592 million by 2035 , accounting for $7.8 \%$ of the adult population. The objective of this study was to record treatments, risk factor control, determinants of glycaemic control and cardiovascular outcomes in type 2 diabetes (T2DM).

Methods: We included adult T2DM patients and followed up for 6 months. Patients were categorised into good (HbA1c <7\%), moderate $(7$ to $8.5 \%)$ and poor control (>8.5\%). We used multiple logistic regression to identify determinants of glycaemic control and outcomes.

Results: We recruited 785 patients with a mean age of $55.43( \pm 11.1)$ years, and $43.8 \%$ were women. At baseline, patients with poor control $(45 \%)$ were younger and from lower socioeconomic strata (73.5\%). At 6 months, the American Diabetes Association (ADA) targets of HbA1c was met only in $27.52 \%$, systolic blood pressure (SBP) in $81.47 \%$ and low density lipoprotein (LDL) cholesterol in $48.86 \%$ patients. Patients with sedentary or low physical activity (Odds ratio 11.51, 95\% confidence interval 3.48, 37.98; $\mathrm{p}<0.001$ ) and with diabetes for a longer duration (OR 1.14 [1.07-1.22], $\mathrm{p}<0.001)$ were more likely to be in poor glucose control. Patients having sedentary or low physical activity (OR 6.66 [1.730-25.63] $\mathrm{p}=0.006)$ and higher LDL cholesterol (OR 1.04 [1.01-1.07], $\mathrm{p}=0.008)$ were more likely to get microvascular complications.

Conclusions: Management of modifiable risk factors and early control of hyperglycaemia should be given more importance.
\end{abstract}

Keywords: T2DM, Cardiovascular risk factors, India

\section{INTRODUCTION}

The prevalence of type 2 diabetes mellitus (T2DM) is growing rapidly worldwide. The global burden of T2DM in 2013 was 382 million and projected to 592 million by 2035 , accounting for $7.8 \%$ of the adult population. ${ }^{1}$ The International Diabetes Federation (IDF), estimates that 63 million people in India had T2DM in 2012 which is projected to rise to 101.2 million by 2030 , an increase of 60.6\%. ${ }^{1}$ Among diabetic patients, cardiovascular disease (CVD) accounts for about $80 \%$ of all mortality and $75 \%$ of all hospitalizations. ${ }^{2,3}$ Diabetics without prior coronary artery disease (CAD) have a similar risk as non-diabetics with prior $\mathrm{CAD}$ and a poorer prognosis. ${ }^{4}$ Although T2DM alone is an independent risk factor, most patients have additional risk factors for macrovascular complications. Hypertension is prevalent in approximately $75 \%$ and dyslipidemia in approximately $70 \%$ of T2DM patients. ${ }^{5}$ Thus hypertension and hyperlipidemia are important targets of therapy in addition to hyperglycaemia in diabetic patients. ${ }^{6}$ The American diabetes association (ADA) guidelines 
recommend the reduction of vascular complications through control of blood glucose, blood pressure, blood lipids, smoking cessation and intensified treatment for primary prevention of CAD. ${ }^{7}$ In the Groningen Initiative to analyse Type 2 diabetes Treatment (GIANTT) registry in the Netherlands, over 4 years found that over half the patients were insufficiently controlled and medications were not promptly adjusted. ${ }^{8}$ In the Chennai Urban Population Study (CUPS), CAD prevalence was $21.4 \%$ among T2DM compared to $9.1 \%$ in normoglycemic subjects. ${ }^{9}$ In Indians, CAD occurs about one decade earlier than in the West. ${ }^{10}$ We searched (PubMed Jan 1960 to June 2013; key words: type 2 diabetes mellitus, cardiovascular risk factors, complications, outcomes, India) and found no Indian studies on risk factor management and determinants of clinical outcomes in T2DM. Sensing an urgent need for studies on CAD in diabetic subjects in India, we aimed to record risk factor control, determine the reasons for poor glycaemic control and estimate determinants of cardiovascular outcomes among T2DM patients at 6 months.

\section{METHODS}

We conducted an observational study with a 6 months follow-up at St. John's Medical College, a tertiary care centre in Bangalore. We included T2DM patients from the endocrinology, medicine and cardiology outpatient departments, on pharmacotherapy. Patients in whom the 6 month follow up were not possible and pregnant women were excluded. Patient recruitment was done over 14 months. The study was approved by the institutional ethics committee and informed consent was obtained from all the participants prior to recruitment.

We estimated sample size, based on the annual cardiovascular event rate in diabetic patients under good and poor control. ${ }^{11}$ Using a risk difference of $2.25 \%$ between the groups and a 95\% confidence interval, sample size was 654 patients. Factoring for a $20 \%$ drop out, we recruited 785 patients. Patients were categorised by their HbA1c levels into good $(<7 \%)$, moderate (between 7 to $8.5 \%$ ) and poor control $(>8.5 \%) .{ }^{8}$ The target levels for good risk factor control are based on ADA guidelines. ${ }^{7}$ The subdivision into classes of moderate and insufficient control was made because it can be expected that prescribers will react differently to levels closer to target compared to more elevated levels. ${ }^{12}$

We recorded demography, lifestyle, socio economic status (education, total family income, occupation, number of dependents), medical history (diabetes onset and duration, co-morbidities) and drug history. Blood pressure, height, weight and blood investigations done in last 3 months were recorded. All patients were followed up once between the first and third months and at 6 months. The data included drugs taken, investigations and clinical outcomes if any in last 6 months. Macrovascular complications included angina pectoris, myocardial infarction, heart failure, stroke, coronary revascularisation, peripheral vascular disease (PVD), amputations or death. Microvascular complication included microalbuminuria, end stage renal disease, retinopathy, and peripheral neuropathy and foot complications. Cardiovascular outcomes were assessed based on clinical, ECG, Echo and laboratory findings.

We summarized data of patients as mean, median and crude rates. Categorical variables were compared using Chi-squared tests. All continuous variables were checked for normality and compared using ANOVA. To assess the determinants of poor glycaemic control and macro vascular complications at 6 months, we used multivariable logistic regression analysis. We report the adjusted odds ratios (adjusted for age and gender) with their $95 \%$ confidence intervals. A $p$ value $<0.05$ was considered significant for all tests. Statistical analyses were performed using commercially available software (SPSS version 17).

\section{RESULTS}

We recruited 785 T2DM patients and their characteristics are summarised in Table 1 . Mean age was $55.4( \pm 11.1)$ years, median duration of diabetes was 6.0 years (IQR: 2, 12) and $43.8 \%$ were women. Majority were from lower middle $(48.9 \%)$ and poor $(24.6 \%)$ social classes. Over half the patients had hypertension (61.8\%) and dyslipidemia (60.4\%) and $45 \%$ had both. At baseline, 391 (49.8\%) had either microvascular or macro vascular complications with neuropathy $(20.4 \%)$ and ischemic heart disease $(15.5 \%)$ being the commonest. Data on fasting (FBS), post prandial sugars (PPBS) and HbA1c levels were available for $84 \%, 77.3 \%$ and $56.1 \%$ patients respectively. The mean FBS, 2 hour PPBS and HbA1c were $157.5 \pm 72.9 \mathrm{mg} / \mathrm{dL}, \quad 232.8 \pm 98.1 \mathrm{mg} / \mathrm{dL}$ and $8.7 \pm 2.2 \%$ respectively. Data on lipids were available for $53 \%$ patients. Micro albuminuria was present in 122 $(15.5 \%)$ patients out of $31.9 \%$ in whom it was checked. Eye checks were done in $559(71.2 \%)$ patients and diabetic retinopathy was present in $66(8.4 \%)$ patients.

Table 2 depicts patient characteristics by levels of glucose control.

Patients were categorised by their HbA1c levels into good $(<7 \%)$, moderate (between 7 to $8.5 \%$ ) and poor control $(>8.5 \%) .{ }^{8}$ Patients in the poor control group were younger [53.14 \pm 11.9 years] than the patients in the good and moderate control $[59.41 \pm 11.2, \quad 56.17 \pm 10.4$ years $\mathrm{p}<0.001]$. The proportion of patients in poor control group from the lower middle class and poor backgrounds were higher $(82.8 \%$ versus $17.2 \%, \mathrm{p}=0.017)$. The total cholesterol levels $(185.1 \mathrm{mg} / \mathrm{dL}$ in poor control versus $174.0 \mathrm{mg} / \mathrm{dL}$ in moderate and $168.3 \mathrm{mg} / \mathrm{dL}$ in good control, $\mathrm{p}<0.05)$ and microvascular complications were higher in the poor control group compared to other groups (59.9\% in poor control versus $24.3 \%$ in moderate and $15.8 \%$ in good control, $\mathrm{p}<0.01)$. 
Table 1: Baseline characteristics of patients with T2DM.

\begin{tabular}{|c|c|}
\hline Parameter & Overall (785) \\
\hline Age (years) (SD) & $55.43(11.06)$ \\
\hline Male gender $[\mathrm{n}(\%)]$ & $441(56.2)$ \\
\hline \multicolumn{2}{|c|}{ Socio- economic status [749 $(95.4 \%)]$} \\
\hline Rich & $40(5.1)$ \\
\hline Upper middle & $124(15.8)$ \\
\hline Lower middle & $384(48.9)$ \\
\hline Poor & $201(24.6)$ \\
\hline BMI (kg/m2) & $26.0(3.95)$ \\
\hline \multicolumn{2}{|l|}{ Diabetes duration [n (\%)] } \\
\hline$<2$ years & $159(20.3)$ \\
\hline $2-5$ years & $213(27.1)$ \\
\hline$>5$ years & $413(52.6)$ \\
\hline \multicolumn{2}{|l|}{ Physical activity [n (\%)] } \\
\hline Sedentary/low & $322(41.0)$ \\
\hline High/moderate & $463(59.0)$ \\
\hline \multicolumn{2}{|l|}{ CV risk factors } \\
\hline Smoking [Current] $(\%)$ & $74(9.4)$ \\
\hline Hypertension [n (\%)] & $485(61.8)$ \\
\hline Dyslipidemia [n (\%)] & $474(60.4)$ \\
\hline HTN + Dyslipidemia [n (\%)] & $353(45.0)$ \\
\hline \multicolumn{2}{|l|}{ Blood investigations } \\
\hline FBG (mg/dL) (SD) & $157.54(72.9)$ \\
\hline 2hPPBG (mg/dL) (SD) & $232.84(98.1)$ \\
\hline Total cholesterolemia (mg/dL) (SD) & $178.70(48.8)$ \\
\hline HDL (mg/dL) (SD) & $39.67(15.1)$ \\
\hline LDL (mg/dL) (SD) & $106.55(36.6)$ \\
\hline SBP (mmHg) (SD) & $128.00(17.2)$ \\
\hline $\mathrm{DBP}(\mathrm{mmHg})(\mathrm{SD})$ & $79.99(8.3)$ \\
\hline $\begin{array}{l}\text { Any Microvascular complications } \\
{[\mathrm{n}(\%)]}\end{array}$ & $298(38.0)$ \\
\hline Retinopathy [n (\%)] & $86(10.9)$ \\
\hline Nephropathy [n (\%)] & $24(3.1)$ \\
\hline Neuropathy [n (\%)] & $160(20.4)$ \\
\hline Microalbuminuria [n (\%)] & $122(15.5)$ \\
\hline $\begin{array}{l}\text { Any Macrovascular complications } \\
{[\mathrm{n}(\%)]}\end{array}$ & $161(20.5)$ \\
\hline $\mathrm{MI}[\mathrm{n}(\%)]$ & $49(6.2)$ \\
\hline IHD [n (\%)] & $122(15.5)$ \\
\hline Stroke/TIA [n (\%)] & $36(4.6)$ \\
\hline $\operatorname{PVD}[\mathrm{n}(\%)]$ & $11(1.4)$ \\
\hline $\begin{array}{l}\text { Either macrovascular or } \\
\text { microvascular complications [n } \\
(\%)]\end{array}$ & $391(49.8)$ \\
\hline
\end{tabular}

\section{Treatments and outcomes}

Dietary advice was given in $95.8 \%$ patients, among which $83.6 \%$ reported following it at 6 months. Exercise advice was given in $92.9 \%$ patients. At 6 months, majority reported moderate physical activity (50.7\%), 33.9\% reported low physical activity and $7.1 \%$ reported sedentary lifestyle. About half the patients (46.3\%) were on 2 classes of antidiabetic agents. The most commonly prescribed was metformin $(84.1 \%)$ followed by sulphonylureas (SU) (50.7\%). Thiazolidinediones (TZD) were prescribed in $8.9 \%$ and alpha glucosidase inhibitors in $3.1 \%$ patients. Among newer agents, gliptins were prescribed in $71(9 \%)$ and glucagon like peptide-1(GLP1) analogues exenatide, liraglutide were prescribed in 5 $(0.7 \%)$ patients. Insulin was prescribed in $317(40.4 \%)$ patients and 253 (32.2) patients were on oral antidiabetic agents and insulin. At baseline, almost all (93.8\%) patients reported taking over $80 \%$ of prescribed doses in the preceding month.

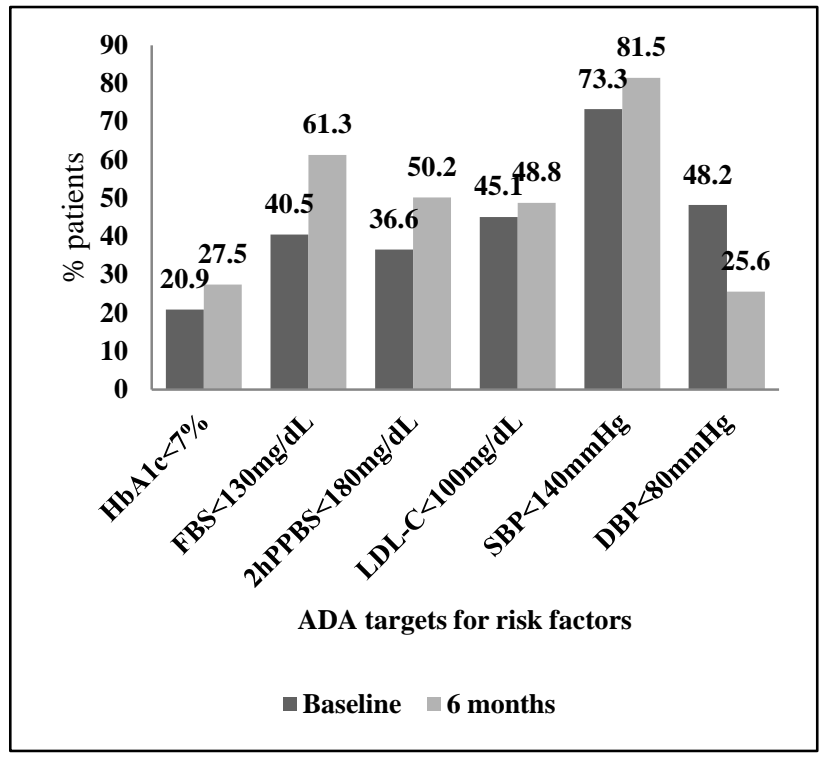

Figure 1: Patients who met ADA targets for risk factor control.

Antidiabetic drugs at baseline were compared by levels of blood glucose control. In those with good control, $43.5 \%$ were using 2 drug classes and $37 \%$ were on monotherapy $(\mathrm{p}<0.001)$. In the poor control group, $13.1 \%$ were on monotherapy and $28.3 \%$ were on three or more drug classes $(\mathrm{p}<0.001)$. Also, $47.7 \%$ in poor control group were on OHAs alone.

Of $485(61.8 \%)$ who had hypertension, 26 (5.4\%) were not on any antihypertensive medication and $31.3 \%$ were on monotherapy. There were $34.6 \%$ on fixed dose combinations (supplementary file A; Table A.1). Angiotensin converting enzyme inhibitors (ACEIs) were prescribed in $23.9 \%$, calcium channel blockers (CCBs) in $162(33.4 \%)$ and beta blockers (BB) were prescribed in $142(29.3 \%)$ patients. Among those prescribed BBs, 51 (35.9\%) had CAD. Among those with good control of systolic blood pressure (SBP $<140 \mathrm{mmHg}$ ), majority $(69.7 \%)$ were on one or two drug combinations. (Supplementary file A; Table A.2). In $7.6 \%$ patients antihypertensive medications were changed or dose altered at 6 months.

Statins were used in $471(60.0 \%)$ patients. Among 417 $(53.1 \%)$ patients in whom LDL data were available, 229 
(54.9\%) had raised LDL-C at baseline (>100 mg/dL). In patients with raised LDL, $138(60.3 \%)$ were on lipid lowering drugs and $91(39.7 \%)$ were not any lipid lowering drugs. Anti-platelets were used in $49.7 \%$ patients (aspirin 313 [39.9\%] and clopidogrel in 124 [15.8\%]). Among them, 26.4\% had history of CAD. At 6 months there was improvement in $\mathrm{HbA} 1 \mathrm{c}, \mathrm{FBS}$ and 2 hour PPBS levels. There was $8.1 \%$ reduction in $\mathrm{HbA1c}$ $(\mathrm{p}<0.001), 14.7 \%$ reduction in fasting sugar $(\mathrm{p}<0.001)$ and $14.6 \%$ reduction in post prandial sugars $(\mathrm{p}<0.001)$ over 6 months. The SBP, DBP and lipids (mean total cholesterol, LDL, HDL and triglyceride) did not differ significantly over 6 months.

Table 2: Baseline patient characteristics by levels of glucose control.

\begin{tabular}{|c|c|c|c|c|}
\hline $\begin{array}{l}\text { Variables } \\
N=440\end{array}$ & $\begin{array}{l}\text { Good control } \\
\text { HbA1c }<7 \% \\
\mathrm{~N}=92(20.9 \%)\end{array}$ & $\begin{array}{l}\text { Moderate control } \\
\text { HbA1c: } 7-8.5 \% \\
\mathrm{~N}=150(\mathbf{3 4 . 1} \%)\end{array}$ & $\begin{array}{l}\text { Poor control } \\
\text { HbA1c }>8.5 \% \\
N=198(45 \%)\end{array}$ & p value \\
\hline Mean Age (years) (SD) & $59.41(11.1)$ & $56.17(10.4)$ & $53.14(11.9)$ & $<0.001$ \\
\hline \multicolumn{5}{|l|}{ Gender $[\mathrm{n}(\%)]$} \\
\hline Male & $61(66.3)$ & $66(44.0)$ & $102(51.5)$ & \multirow{2}{*}{0.003} \\
\hline Female & $31(33.7)$ & $84(56.0)$ & $96(48.5)$ & \\
\hline BMI $\left(\mathrm{Kg} / \mathrm{m}^{2}\right)$ & $27.2(4.7)$ & $26.7(3.9)$ & $25.6(3.5)$ & 0.216 \\
\hline \multicolumn{5}{|l|}{ Socioeconomic status $[\mathrm{n}(\%)]$} \\
\hline Rich & $8(29.6)$ & $12(44.4)$ & $7(25.9)$ & \multirow{4}{*}{0.017} \\
\hline Upper middle & $18(26.1)$ & $24(34.8)$ & $27(39.1)$ & \\
\hline Lower middle & $54(23.8)$ & $73(32.2)$ & $100(44.1)$ & \\
\hline Poor & $12(10.3)$ & $41(35.0)$ & $64(54.7)$ & \\
\hline \multicolumn{5}{|l|}{ Diabetes duration [n (\%)] } \\
\hline$<2$ years & $16(17.0)$ & $31(33.0)$ & $47(50.0)$ & \multirow{3}{*}{0.074} \\
\hline $2-5$ years & $32(24.6)$ & $53(40.8)$ & $45(34.6)$ & \\
\hline$>5$ years & $44(20.4)$ & $66(30.6)$ & $106(49.1)$ & \\
\hline \multicolumn{5}{|l|}{ Physical activity [n (\%)] } \\
\hline Sedentary/low & $23(25.0)$ & $74(49.3)$ & $80(45.2)$ & \multirow{2}{*}{0.001} \\
\hline High/moderate & $69(75.0)$ & $76(50.7)$ & $118(59.6)$ & \\
\hline \multicolumn{5}{|l|}{$\mathrm{CV}$ risk factors } \\
\hline Smoking [current] (\%) & $9(19.1)$ & $16(34.0)$ & $22(46.8)$ & 0.030 \\
\hline Hypertension [n (\%)] & $63(24.2)$ & $94(36.2)$ & $103(39.6)$ & 0.016 \\
\hline Dyslipidemia [n (\%)] & $72(25.5)$ & $98(34.8)$ & $112(39.7)$ & 0.002 \\
\hline \multicolumn{5}{|l|}{ Blood investigations } \\
\hline FBS $(\mathrm{mg} / \mathrm{dL})(\mathrm{SD})$ & $115.2(27.1)$ & $134.5(32.7)$ & $188.1(69.2)$ & $<0.001$ \\
\hline 2hPPBG (mg/dL) (SD) & $172.4(57.8)$ & $192.3(57.0)$ & $287.6(91.4)$ & $<0.001$ \\
\hline Total cholesterolemia (mg/dL) (SD) & $168.3(56.9)$ & $174.0(38.0)$ & $185.1(50.5)$ & 0.041 \\
\hline HDL (mg/dL) (SD) & $44.4(12.9)$ & $39.2(16.7)$ & $38.5(17.0)$ & 0.060 \\
\hline $\mathrm{LDL}(\mathrm{mg} / \mathrm{dL})(\mathrm{SD})$ & $89.3(38.2)$ & $109.3(36.3)$ & $108.7(32.7)$ & 0.001 \\
\hline SBP (mmHg) (SD) & $130.4(19.5)$ & $130.4(18.5)$ & $128.2(16.1)$ & 0.432 \\
\hline $\mathrm{DBP}(\mathrm{mmHg})(\mathrm{SD})$ & $79.7(8.9)$ & $80.6(7.6)$ & $81.7(9.4)$ & 0.175 \\
\hline Any Microvascular complications [n (\%)] & $28(15.8)$ & $43(24.3)$ & $106(59.9)$ & $<0.001$ \\
\hline Retinopathy [n (\%)] & $8(20.5)$ & $7(17.9)$ & $24(61.5)$ & 0.053 \\
\hline Nephropathy [n (\%)] & $0(0.0)$ & $1(20.0)$ & $4(80.0)$ & 0.256 \\
\hline Neuropathy [n (\%)] & $10(11.1)$ & $23(25.6)$ & $57(63.3)$ & $<0.001$ \\
\hline Diabetic foot $(\%)$ & $5(23.8)$ & $3(14.3)$ & $13(61.9)$ & 0.134 \\
\hline Any macrovascular complications (\%) & $15(20.0)$ & 37 (49.3) & $23(30.7)$ & 0.006 \\
\hline MI (\%) & $8(33.3)$ & $11(45.8)$ & $5(20.8)$ & 0.045 \\
\hline $\operatorname{IHD}(\%)$ & $5(12.5)$ & $22(55.0)$ & $13(32.5)$ & 0.013 \\
\hline Stroke/TIA (\%) & $3(13.6)$ & $12(54.5)$ & $7(31.8)$ & 0.115 \\
\hline PVD (\%) & $0(0.0)$ & $1(33.3)$ & $2(66.7)$ & 0.623 \\
\hline
\end{tabular}

\# HbA1c values were available only for 440 patients at baseline 
Table 3: Treatment of T2DM at baseline with mean duration of DM and HbA1c levels.

\begin{tabular}{|c|c|c|c|}
\hline Therapy & $\mathbf{N}(\%)(\mathbf{7 8 5})$ & Mean duration of DM (years) & Mean HbA1c* \\
\hline OHA alone & $459(58.5)$ & 5.5 & 8.2 \\
\hline OHA + Insulin & $253(32.2)$ & 12.1 & 9.9 \\
\hline Insulin alone & $61(7.8)$ & 12.8 & 10.2 \\
\hline \multicolumn{4}{|l|}{ Monotherapy } \\
\hline Metformin alone & $128(16.3)$ & 3.7 & 7.4 \\
\hline Sulphonylurea alone & $38(4.8)$ & 3.7 & 8.3 \\
\hline Gliptins alone & $5(0.6)$ & 6.4 & 6.7 \\
\hline Insulin alone & $61(7.8)$ & 12.8 & 10.2 \\
\hline \multicolumn{4}{|l|}{ Dual therapy } \\
\hline Sulphonylurea + Insulin & $13(1.7)$ & 12.6 & 10.6 \\
\hline Metformin + Insulin & $136(17.3)$ & 11.9 & 9.9 \\
\hline Metformin + alphaglucosidase (-) & $4(0.5)$ & 6.8 & 8.4 \\
\hline Sulphonylurea + Metformin & $187(23.8)$ & 7.7 & 8.6 \\
\hline Sulphonylurea + Gliptin & $1(0.1)$ & 8.9 & 8.2 \\
\hline Sulphonylurea + Glitazone & $3(0.4)$ & 9.8 & 8.7 \\
\hline Metformin + Glitazone & $5(0.6)$ & 10.2 & 8.8 \\
\hline Metformin + Gliptin & $12(1.5)$ & 9.4 & 8.2 \\
\hline Insulin + alphaglucosidase (-) & $3(0.4)$ & 14.8 & 9.0 \\
\hline \multicolumn{4}{|l|}{ Triple therapy } \\
\hline Metformin + Sulphonylureas + Insulin & $72(9.2)$ & 12.8 & 10.7 \\
\hline Metformin + Sulphonylureas + Glitazone & $33(4.2)$ & 10.2 & 8.8 \\
\hline Metformin + Sulphonylureas + Gliptins & $32(4.1)$ & 8.9 & 8.9 \\
\hline \multicolumn{4}{|l|}{ Number of drug classes used } \\
\hline 1 drug class & $232(29.6)$ & & \\
\hline 2 drug class & $364(46.3)$ & & \\
\hline$\geq 3$ drug class & $189(24.1)$ & & \\
\hline Statins & $471(60.0)$ & & \\
\hline Anti-platelets & $390(49.7)$ & & \\
\hline
\end{tabular}

Table 4: Drug therapy at baseline by levels of glucose control.

\begin{tabular}{|c|c|c|c|c|}
\hline $\begin{array}{l}\text { Drugs } \\
(n=440) \#\end{array}$ & $\begin{array}{l}\text { Good control } \\
\text { HbA1c }<7 \% \\
\mathbf{N}=92(\mathbf{2 0 . 9} \%)\end{array}$ & $\begin{array}{l}\text { Moderate control } \\
\text { HbA1c: } \mathbf{7 - 8 . 5 \%} \\
\mathrm{N}=\mathbf{1 5 0}(\mathbf{3 4 . 1 \% )}\end{array}$ & $\begin{array}{l}\text { Poor control } \\
\text { HbA1c>8.5\% } \\
\mathbf{N}=\mathbf{1 9 8}(\mathbf{4 5 \%})\end{array}$ & p value \\
\hline \multicolumn{5}{|c|}{ Number of antidiabetic drug classes used } \\
\hline 1 drug class $(n=97)$ & $34(37.0)$ & $37(24.7)$ & $26(13.1)$ & \multirow{3}{*}{$<0.001$} \\
\hline 2 drug class $(n=230)$ & $40(43.5)$ & $74(49.3)$ & $116(58.6)$ & \\
\hline$\geq 3$ drug class $(n=113)$ & $18(19.6)$ & $39(26.0)$ & $56(28.3)$ & \\
\hline \multicolumn{5}{|l|}{ Treatment modality } \\
\hline OHA alone & $68(75.6)$ & $125(84.5)$ & $94(47.7)$ & \multirow{3}{*}{$<0.001$} \\
\hline $\mathrm{OHA}+$ Insulin & $22(24.4)$ & $20(13.5)$ & $93(47.2)$ & \\
\hline Insulin alone & $0(0.0)$ & $3(2.0)$ & $10(5.1)$ & \\
\hline Statins $(n=282)$ & $72(25.5)$ & $98(34.8)$ & $112(39.7)$ & 0.001 \\
\hline Anti-platelets $(\mathrm{n}=213)$ & $61(28.6)$ & $70(32.9)$ & $82(38.5)$ & 0.047 \\
\hline
\end{tabular}

\# HbA1c values were available only for 440 patients at baseline

At 6 months, the ADA recommended target levels for $(\mathrm{HbA} 1 \mathrm{c}<7 \%)$ were met in $27.52 \%$, FBS in $61.30 \%$, PPBS in $50.25 \%$, SBP in $81.47 \%$, DBP in $25.61 \%$ and LDL cholesterol in $48.86 \%$ patients (Figure 1). Patients with sedentary or low physical activity (OR 11.51 [3.48-37.98] $\mathrm{p}<0.001$ ), with diabetes for a longer duration (OR 1.14 [1.07-1.22], $\mathrm{p}<0.001$ ), higher baseline HbA1c (OR 1.54 [1.04-2.27], $\mathrm{p}=0.030$ ), higher baseline FBS (OR 1.05 [1.02-1.07], $\mathrm{p}<0.001)$ and higher baseline PPBS (OR 
1.02 [ 1.01-1.03], $\mathrm{p}<0.001)$ are more likely to be in poor glucose control (supplementary file A; Table A.3).

We were able to follow up $623(79.6 \%)$ patients at 6 months. At this time, $3(0.4 \%)$ had died, $14(2.2 \%)$ had macrovascular complications (myocardial infarction, heart failure, stroke, PVD) and 38 (6.1\%) developed microvascular complications (peripheral neuropathy, microalbuminuria, retinopathy). Patients with sedentary or low physical activity (OR 6.658 [1.730-25.627] $\mathrm{p}=$ $0.006)$, prior CV event (OR 3.313 [1.068 - 10.278], $\mathrm{p}=$ 0.038 ) and higher LDL cholesterol (OR 1.041 [1.010$1.073], \mathrm{p}=0.008$ ) were more likely to get macrovascular complications (supplementary file; Table A.3).

\section{Supplementary file A}

\section{Table A (1): Treatment of hypertension in T2DM} patients at baseline.

\begin{tabular}{|ll|}
\hline Therapy & $\mathbf{N}(\%)(\mathbf{4 8 5})$ \\
\hline None & $26(5.4)$ \\
\hline 1 drug class & $152(31.3)$ \\
\hline 2 drug classes & $168(34.6)$ \\
\hline 3 drug classes & $105(21.6)$ \\
\hline$>3$ drug classes & $34(7.0)$ \\
\hline Fixed dose combinations & $162(33.4)$ \\
\hline Monotherapy & \\
\hline ARBs & $63(13.0)$ \\
\hline ACE inhibitors & $44(9.1)$ \\
\hline CCBs & $23(4.7)$ \\
\hline Diuretics & $1(0.2)$ \\
\hline Beta blockers & $20(4.1)$ \\
\hline Alpha + beta blocker & $1(0.2)$ \\
\hline Dual therapy & \\
\hline ARB + Diuretic & $65(13.4)$ \\
\hline ARB + CCB & $17(3.5)$ \\
\hline CCB + beta blocker & $17(3.5)$ \\
\hline ACE inhibitor + diuretic & $17(3.5)$ \\
\hline ARB + beta blocker & $15(3.1)$ \\
\hline ACEI + beta blocker & $10(2.1)$ \\
\hline ACEI + alpha beta blocker & $9(1.9)$ \\
\hline CCB + ACE inhibitors & $6(1.2)$ \\
\hline Beta blocker + diuretic & $5(1.0)$ \\
\hline CCB + Diuretic & $3(0.6)$ \\
\hline ARB + alpha beta blocker & $1(0.2)$ \\
\hline
\end{tabular}

\section{DISCUSSION}

In our study, over half of the patients had hypertension and dyslipidemia as comorbidity and half of the patients had either macrovascular or microvascular complications at baseline. HbA1c target levels were not achieved in majority $(79.1 \%)$ of patients. Those in poor control were younger and from lower socioeconomic backgrounds. Also among patients with diabetes duration less than 2 years, $50 \%$ were under poor control. There was an overall reduction in the HbA1c, FBS and PPBS levels over 6 months but the ADA targets were not met in many patients. Sedentary lifestyle and long disease duration were found to be important risk factors for poor control. Low levels of glycaemic control has been similarly shown in a cross-sectional study from Asian countries and other studies done in Thailand and Pakistan. ${ }^{12-15}$ A systematic review by Sanal TS et al on studies done in India from 1980 to 2010, showed diabetes control was poor among younger adults $($ O.R. $=1.61,95 \%$ C.I, $1.11,2.33) .{ }^{16}$ This poses serious implications on development of long term complications at a relatively young age. The 10 year follow up of the Chennai Urban Population Study (CUPS) showed a rapid reversal of socioeconomic gradient for diabetes and cardio metabolic risk factors and high prevalence in urban poor. ${ }^{17}$ This trend could be because of rapid urbanisation, 'fast food' culture, life style changes and delay in timely treatment among the poor. High LDL levels and microvascular complications associated with poor control was seen in other studies also. ${ }^{13,18}$ This highlights the importance of glycaemic control to prevent or delay micro vascular complications. A cross sectional study from India in 2005 , demonstrates that a substantial proportion fail to meet ADA target levels for $\mathrm{HbA} 1 \mathrm{c}$ and LDL cholesterol similar to our study. ${ }^{19}$ Only $10 \%$ met target levels for all 3 risk factors at baseline in our study. In cross-sectional analysis of the prospective Diabetes Registry to Improve Vascular Events (DRIVE, 20052006) cohort, on 3002 patients, only $21 \%$ achieved the combined targets for SBP, A1c and LDL-C. ${ }^{20}$

Metformin, sulfonylureas and insulin were most prescribed in our study, due to their proven efficacy, known side effects and low cost. TZDs were commonly used in combination with SU and metformin in the subjects with relatively a longer duration of diabetes. Similar results were seen in study by Kosachunhanun $\mathrm{N}$ et al. ${ }^{18}$ Patients with less duration of diabetes and lower mean $\mathrm{HbA1c}$ received OHAs alone while those with long standing diabetes and less favourable glycaemic control were on insulin with or without OHA. This indicates the stepwise approach to therapy is being followed in our hospital. Among patients in poor control, about half were on OHAs alone. This might reflect under usage or delay in starting insulin therapy which often leads to accumulation of glycaemic burden in patients before intensification of therapy. The ADA7 recommend initiation of insulin in patients with elevated $\mathrm{HbA} 1 \mathrm{c}$ at the outset only if glycaemia target is not achieved by maximal tolerated dose of monotherapy in 3-6 months. An observational study on $66,726 \mathrm{~T} 2 \mathrm{DM}$ patients in India also noted suboptimal use of insulin. ${ }^{15}$ The delay in initiating insulin therapy may be probably due to worry about daily injections, fear of hypoglycaemia, modification of lifestyle due to insulin and dependence on insulin for life. An average patient accumulates 5 years of $\mathrm{HbA} 1 \mathrm{C}$ more than $8 \%$, and 10 years of $\mathrm{HbA} 1 \mathrm{C}$ more than $7 \%$ before insulin therapy is initiated. ${ }^{23}$ The early glycaemic control has beneficial effect on diabetic complications even if later returned to poorer metabolic control which is known as 'metabolic memory'. ${ }^{24}$ So there 
is an urgent need to change the clinical inertia in intensification of treatment early to reduce the glycaemia burden and prevent complications.

ARBs were most commonly prescribed antihypertensive, followed by diuretics and CCBs in our study in contrast to a study in North India where ACE inhibitors were prescribed most, followed by $\mathrm{ARBs}$ and $\mathrm{CCBs} .{ }^{24}$ The ADA prefers RAS blockers for initial therapy due to their superior cardiovascular and renal protective effects. ${ }^{25}$ The use of ACE inhibitors in combination therapy was suboptimal in our study, possibly due to adverse effects like dry cough associated with ACE inhibitors. The 2014 hypertension guidelines recommend initiating antihypertensive treatment using thiazide diuretic, CCB or
RAS blockers. ${ }^{26}$ Major concern with the use of diuretic is the tendency to worsen hyperglycemia, but this effect was found to be small and did not produce more CV events compared with the other drug classes. ${ }^{27}$ Majority $(81.47 \%)$ achieved target SBP in our study at 6 months. The 2014 hypertension guidelines ${ }^{26}$ and 2015 ADA guidelines $^{25}$ recommend target SBP below $140 \mathrm{~mm} \mathrm{Hg}$ and DBP below $90 \mathrm{~mm} \mathrm{Hg}$. In our study, among patients with raised LDL cholesterol, $39.5 \%$ patients were not on any lipid lowering treatment. A meta-analysis on the effect of statins on LDL cholesterol, recommended using statins to lower LDL cholesterol and reduce CAD risk by almost $60 \% .^{28}$ Among patients with increased cardiovascular risk $(39.6 \%)$, anti-platelets were prescribed for primary prevention in $66.2 \%$ patients.

Table A (2): Number of drugs for hypertension by SBP control at baseline.

\begin{tabular}{|c|c|c|c|c|}
\hline $\begin{array}{l}\text { Antihypertensive } \\
\text { medications } \\
(472) *\end{array}$ & $\begin{array}{l}\text { Good control } \\
\text { SBP }<140 \mathrm{mmHg} \\
\mathbf{N}=\mathbf{2 8 7}(\mathbf{6 0 . 8 \%})\end{array}$ & $\begin{array}{l}\text { Moderate control } \\
\text { SBP: } 140-160 \mathrm{mmHg} \\
\mathrm{N}=130(27.5 \%)\end{array}$ & $\begin{array}{l}\text { Poor control } \\
\text { SBP> } 160 \mathrm{mmHg} \\
\mathbf{N}=\mathbf{5 5}(\mathbf{1 1 . 7} \%)\end{array}$ & p value \\
\hline None $(n=22)$ & $15(5.2)$ & $7(5.4)$ & $0(0.0)$ & \multirow{5}{*}{0.002} \\
\hline 1 drug class $(n=148)$ & $101(35.2)$ & $40(30.8)$ & $7(12.7)$ & \\
\hline 2 drug classes $((n=166)$ & $99(34.5)$ & $48(36.9)$ & $19(34.5)$ & \\
\hline 3 drug classes $(n=102)$ & $57(19.9)$ & $24(18.5)$ & $21(38.2)$ & \\
\hline$>3$ drug classes $(n=34)$ & $15(5.2)$ & $11(8.5)$ & $8(14.5)$ & \\
\hline
\end{tabular}

Table A (3): Risk for poor glucose control* and macro-vascular complications at 6 months.

\begin{tabular}{|lllll|}
\hline & \multicolumn{1}{l}{ Poor control of blood glucose } & \multicolumn{2}{l|}{ Macrovascular complications } \\
\hline Variables & Adjusted OR (95\% CI) & p value & Adjusted OR (95\% CI) $^{\#}$ & p value \\
\hline Baseline HbA1c & $1.54(1.04-2.28)$ & 0.030 & - & - \\
\hline Baseline FBS & $1.05(1.03-1.08)$ & $<0.001$ & - & - \\
\hline Baseline PPBS & $1.02(1.01-1.03)$ & $<0.001$ & - & - \\
\hline OHA alone & 1 & - & - & - \\
\hline OHA + Insulin & $2.97(0.56-15.74)$ & 0.918 & - & - \\
\hline Insulin alone & $2.60(1.17-5.79)$ & 0.002 & - & - \\
\hline No use of statins & $1.40(0.67-2.94)$ & 0.376 & - & - \\
\hline $\begin{array}{l}\text { Sedentary/low physical activity } \\
\text { (versus moderate/high) }\end{array}$ & $11.51(3.49-37.98)$ & $<0.001$ & $6.66(1.73-25.63)$ & 0.006 \\
\hline Diabetes duration & $1.15(1.07-1.22)$ & $<0.001$ & $1.05(0.99-1.12)$ & 0.123 \\
\hline Prior CV event & -- & -- & $3.31(1.07-10.28)$ & 0.038 \\
\hline Total cholesterol & -- & -- & $1.01(0.99-1.02)$ & 0.279 \\
\hline LDL - C & -- & -- & $1.04(1.01-1.07)$ & 0.008 \\
\hline
\end{tabular}

*poor control of glucose defined as HbA1c> 7\%; \# Adjusted for age and gender; Baseline HbA1c, FBS, Antidiabetic medications, No use of statins was not significant for macrovascular complications in univariate analysis

HbA1c data were available in $28.5 \%$ whereas FBS and PPBS data were available in more than $60 \%$ in our study. This may be because of high cost of HbA1c testing that may not be affordable to many coming to our hospital. The fasting and post prandial sugar values may not reveal the true glycaemic status of the patient. Sedentary or low physical activity was found to be highest modifiable predictor for insufficient glycaemic control. Among treatment related factors, compared to patients who were on OHAs alone, those on insulin alone or in combination with OHA were associated with increased odds of insufficient glycaemic control. The study by Khattab ${ }^{18}$ showed longer diabetes duration and non-adherence to lifestyle as risk factors for poor glycaemic control. We 
found sedentary lifestyle, increased LDL cholesterol and prior CV event as significant predictors for macrovascular complications whereas Ciardullo found smoking as a significant predictor for macro-vascular complications. $^{29}$

This study gives an overview of the cardiovascular risk factors, prescription patterns and determinants of clinical outcomes in T2DM at a tertiary care hospital. The study has several limitations. First, this was a single centre study and patterns of drug usage may be different in different health care settings. Follow up data were obtained in $79.6 \%$. Due to the short follow up period we are unable to comment on long term clinical outcomes.

The potentially modifiable risk factors like sedentary life style and high LDL cholesterol should be addressed more aggressively. Individualizing therapeutic goals and treatments to meet targets safely and without delay remains the key factor in improving patient outcomes.

\section{ACKNOWLEDGEMENTS}

Authors would like to acknowledge Seena Thomas and Nisha George, statisticians at St John's Research Institute, Bangalore for their contributions. Authors also thank the faculty of department of Pharmacology, St John's Medical College, Bangalore for their valuable inputs in conduct of this study.

\section{Funding: No funding sources}

Conflict of interest: None declared

Ethical approval: The study was approved by the Institutional Ethics Committee

\section{REFERENCES}

1. International Diabetes Federation. IDF Diabetes Atlas, $6^{\text {th }}$ edn. Brussels, Belgium: International Diabetes Federation, 2013. Available at http://www.idf.org/diabetesatlas. Accessed on 13 December 2013.

2. Khalil H, Mc Namara K, Pan Y. Multiple pharmacological interventions targeting cardiovascular disease risk factors in individuals with type 2 diabetes-systematic review. Journal of Diabetes Research and Clinical Metabolism. 2013;2(1):9.

3. Mohan V, Venkatraman JV, Pradeepa R. Epidemiology of cardiovascular disease in type 2 diabetes: the Indian scenario. J Diabetes Sci Technol. 2010;4(1):158-70.

4. Malmberg K, Yusuf S, Gerstein HC, Brown J, Zhao $\mathrm{F}$, Hunt $\mathrm{D}$, et al. Impact of diabetes on long-term prognosis in patients with unstable angina and nonQ-wave myocardial infarction: results of the OASIS (Organization to Assess Strategies for Ischemic Syndromes) Registry. Circulation. 2000;102(9):10149.
5. Stolar MW. Defining and achieving treatment success in patients with type 2 diabetes mellitus. Mayo Clin Proc. 2010;85(12 Suppl):S50-59.

6. Greving JP, Denig P, de Zeeuw D, Bilo HJ, HaaijerRuskamp FM. Trends in hyperlipidemia and hypertension management in type 2 diabetes patients from 1998-2004: a longitudinal observational study. Cardiovasc Diabetol. 2007;6:25.

7. Diagnosis and classification of diabetes mellitus. Diabetes Care. 2013;36 Suppl 1:S67-74.

8. Voorham J, Haaijer-Ruskamp FM, van der MK, de Zeeuw D, Wolffenbuttel BH, Hoogenberg K, et al. Identifying targets to improve treatment in type 2 diabetes; the Groningen Initiative to analyse Type 2 diabetes Treatment (GIANTT) observational study. Pharmacoepidemiol Drug Saf. 2010;19(10):1078-86.

9. Mohan V, Sandeep S, Deepa R, Shah B, Varghese C. Epidemiology of type 2 diabetes: Indian scenario. Indian J Med Res. 2007;125(3):217-30.

10. Xavier D, Pais P, Devereaux PJ, Xie C, Prabhakaran D, Reddy KS, et al. Treatment and outcomes of acute coronary syndromes in India (CREATE): a prospective analysis of registry data. Lancet. 2008;371(9622):1435-42.

11. Adler AI, Stratton IM, Neil HA, Yudkin JS, Matthews DR, Cull CA, et al. Association of glycaemia with macrovascular and microvascular complications of type 2 diabetes (UKPDS 35): prospective observational study. BMJ. 2000;321(7258):412-9.

12. Hayward RA. All-or-nothing treatment targets make bad performance measures. Am J Manag Care. 2007; 13:126-8

13. Chuang LM, Tsai ST, Huang BY, Tai TY. The status of diabetes control in Asia, a cross-sectional survey of 24317 patients with diabetes mellitus in 1998 . Diabet Med. 2002;19(12):978-85.

14. Kosachunhanun N, Benjasuratwong Y, Mongkolsomlit S, Rawdaree P, Plengvidhya N, Leelawatana $\mathrm{R}$, et al. Thailand diabetes registry project: glycemic control in Thai type 2 diabetes and its relation to hypoglycemic agent usage. J Med Assoc Thai. 2006;89 Suppl 1:S66-S71.

15. Mahmood K, Aamir AH. Glycemic control status in patients with type-2 diabetes. J Coll Physicians Surg Pak. 2005;15(6):323-5.

16. Sanal TS, Nair NS, Adhikari P. Factors associated with poor control of type 2 diabetes mellitus: a systematic review and meta-analysis. Journal of Diabetology. 2011;3:1-10.

17. Deepa M, Anjana RM, Manjula D, Narayan KM, Mohan V. Convergence of prevalence rates of diabetes and cardiometabolic risk factors in middle and low income groups in urban India: 10-year follow-up of the Chennai Urban Population Study. J Diabetes Sci Technol. 2011;5(4):918-27.

18. Khattab M, Khader YS, Al Khawaldeh A, Ajlouni K. Factors associated with poor glycemic control among patients with type 2 diabetes. J Diabetes Complications. 2010;24(2):84-9. 
19. Nagpal J, Bhartia A. Quality of diabetes care in the middle- and high-income group populace: the Delhi Diabetes Community (DEDICOM) survey. Diabetes Care. 2006;29(11):2341-8.

20. Braga M, Casanova A, Teoh H, Dawson KC, Gerstein HC, Fitchett DH, et al. Treatment gaps in the management of cardiovascular risk factors in patients with type 2 diabetes in Canada. Can J Cardiol. 2010;26(6):297-302.

21. Mohan V, Shah S, Saboo B. Current glycemic status and diabetes related complications among type 2 diabetes patients in India: Data from the A1chieve Study. J Assoc Physicians India. 2013;61(suppl):125 .

22. Koro CE, Bowlin SJ, Bourgeois N, Fedder DO. Glycemic control from 1988 to 2000 among U.S. adults diagnosed with type 2 diabetes: a preliminary report. Diabetes Care. 2004;27(1):17-20.

23. Holman RR, Paul SK, Bethel MA, Matthews DR, Neil HA. 10-year follow-up of intensive glucose control in type 2 diabetes. $\mathrm{N}$ Engl $\mathrm{J}$ Med. 2008;359(15):1577-89.

24. Dhanaraj E, Raval A, Yadav R, Bhansali A, Tiwari P. Prescription pattern of antihypertensive agents in
T2DM patients visiting tertiary care centre in North India. Int J Hypertens. 2012;2012:520915.

25. American Diabetes Association. Standards of medical care in diabetes 2015. Diabetes Care. 2015;38(suppl 1):S1-93.

26. James PA, Oparil S, Carter BL, Cushman WC, Himmelfarb CD, Handler J, et al. evidence-based guideline for the management of high blood pressure in adults. JAMA. 2014;311(5):507-20.

27. Chobanian AV, Bakris GL, Black HR, Cushman WC, Green LA, Izzo JL, et al. The seventh report of the joint national committee on prevention, detection, evaluation, and treatment of high blood pressure: the JNC 7 report. JAMA. 2003;289(19):2560-72.

28. Law MR, Wald NJ, Rudnicka AR. Quantifying effect of statins on low density lipoprotein cholesterol, ischaemic heart disease, and stroke: systematic review and meta-analysis. BMJ. 2003;326(7404):1423.

29. Ciardullo AV, Daghio MM, Bevini M, Feltri G, Novi $\mathrm{D}$, Fattori G, et al. Joint and distinct risk factors associated with micro- and macrovascular complications in a cohort of type 2 diabetic patients cared through disease management. Acta Diabetol. 2010;47(4):301-8.

Cite this article as: Jose M, Manjunath A, Bantwal G, Xavier D. Cardiovascular risk factors and determinants of clinical outcomes in type 2 diabetic patients at a tertiary-care centre. Int J Basic Clin Pharmacol 2016;5:2227-35. 